\title{
CARACTERIZAÇÃO dOS MACRÓFAGOS PRESENTES NAS LESÕES CUTÂNEAS DA HANSENÍASE: ESTUDO POR MONOCLONAIS
}

Euzenir Nunes SARNO (1), Fátima de Barros Fonseca ALVARENGA (2), Leila Maria Machado VIEIRA (2), \& Paulo R. Cotrim de Souza (3)

\section{R E S U M O}

As lesōes cutâneas de 16 pacientes com hanseníase foram estudadas por imunofluorescência com anticorpos monoclonais anti-monócitos (OKM1 e anti-MO) e antiIa (OKIa). Foi avaliada a atividade de fosfatase ácida utilizando-se naftol AS-B1 fosfato como substrato.

Os macrófagos parecem constituir uma populaçāo heterogênea em relação aos antígenos estudados neste trabalho e quanto a atividade enzimática. Em todas as formas estudadas um grande número de células eram OKIa positivas.

UNITERMOS: Hanseníase; Macrófagos; Anticorpos monoclonais.

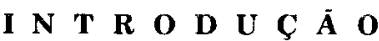

Anticorpos monoclonais dirigidos contra antígenos presentes na superfície celular, tem sido um eficiente método para analisar sub-populaçōes celulares no homem ${ }^{9}$. Se para as diversas sub-populaçōes de linfócitos (ly) foi possível obter monoclonais capazes de identificar todas as células de uma determinada subpopulação ${ }^{8}$ para as células do Sistema Fagocítico Mononuclear (SFM) as dificuldades parecem maiores uma vez que além de sofrerem um processo de maturação a partir da medula, os monócitos do sangue alcançam o tecido e no local da inflamação podem se diferenciar para células epitelióides e células gigantes além de sofrerem modificaçōes morfológicas e funcionais ${ }^{13}$. Nesse proces so de maturação e diferenciação admite-se que antígenos de membrana possam ser perdidos $\mathrm{e}$ outros possam ser expostos dai, a diversidade observada pelos monoclonais para esta catego ria celular ${ }^{12}$

A hanseníase exibe um largo espectro de formas clínicas variando da forma tuberculóide, com alta imunidade, à forma virchowiana com evidência de imunidade celular deprimida ${ }^{7}$. Entre as formas denominadas polares há uma gama de tipos mistos designados "borderline" na classificação de RIDLEY e JOPLING ${ }^{10}$. Em todas as formas as lesōes histológicas se caracterizam pelos diferentes padrões de maturação e diferen ciaçāo mostrados pelas células do SFM. Na forma tuberculóide predominam as células epitelióides com formaçāo de granulomas. E na forma virchowiana predominam os macrófagos madu ros, tipo histióciticos com graus variados de vacuolizaçāo citoplasmática. RIDLEY e JO-

(1) Chefe do Setor de Hanseniase do Instituto Oswaldo Cruz.

(2) Professores Assistentes da Disciplina de Patologia Geral da Universidade do Estado do Rio de Janeiro.

(3) Médico do Serviço de Dermatologia do Hospital de Bonsucesso.

Endereço para correspondência: Fundaçāo Oswaldo Cruz - Setor de Hanseníase - Av. Brasil, 4365 - Manguinhos - CEP 21.041 - Caixa Postal 926 - Rio de Janeiro, Brasil. 
SARNO, E. N. ALVARENGA, F' B. F.: VIEIRA, L. M. M. \& SOUZA. P. R. C de -- Caracterizaçăo dos macrófagos presentes rias lesỏes cutáneas da hanseníase estudo por monoclonais. Rev. Inst. Med. trop. Sáo Paulo, 30 (1): 45-50, 1988

PLING chamaram a atençāo para correlaçāo entre a diversidade do infiltrado celular e o grau de resistência do hospedeiro ${ }^{10}$.

O objetivo do presente trabalho foi analisar a distribuição das subpopulaçōes de macrófagos presentes nas lesóes da hanseníase através de 3 anticorpos monoclonais. Dois deles dirigidos contra antígenos monocitários e outro contra antigenos DR (Ia like).

\section{MATERIAL E METODOS}

Biópsias - Foram selecionados 8 casos de hanseniase do pólo tuberculóide do espectro (formas tuberculóides e "bordeline" tuberculóide) e 8 casos de hanseníase do pólo virchowiano (formas virchowiana e "bordeline" virchowiana). Essas biopsias eram obtidas por "punch" $(5 \mathrm{~mm})$ ou por procedimento cirúrgico. Cada biópsia era dividida em 2 partes imediatamente após a reti rada. Um dos fragmentos era embebido em Tissue -Tek e congelado em nitrogênio líquido até o momento de processar para imunofluorescên cia, utilizando método descrito previamente com detalhe ${ }^{14}$. Cortes de $5 \boldsymbol{\mu}$ foram obtidos em Criostato Cryo-Cut II. American Optical. Após secar ao ar 30 minutos ( $\mathrm{min}$ ) em ambiente refrige rado, os cortes foram fixados em acetona por 10 min. e em seguida lavados 3 vezes por $10 \mathrm{~min}$. cada em tampảo fosfato (PBS) pH 7,4. Os cortes foram incubados à temperatura ambiente em câmara úmida, por $60 \mathrm{~min}$. com anticorpos monoclonais OKIa, OKM1 Orthoclone. Ortho Pharmaceutical Co.) e anti MO gentilmente fornecido por Dr. Van Voorhis da Universidade Rockefeller. Após 3 lavagens em PBS pH 7,4 os cortes foram incubados por $30 \mathrm{~min}$., com IgG anti-ca mundongo biotinilada (Vector Lab.), lavados em 3 banhos de PBS pH 7,4, e tratados com avidinafluoresceina por $30 \mathrm{~min}$. Finalmente lavados em PBS, fixados em formol tamponado a $10 \%$ sendo as lâminas montadas ern Elvanol (polivinil ál cool da Sigma).

A leitura foi realizada em Microscópio SM 20 Leitz-Dialux.

Após exame dos cortes, fez-se a quantificaçâo das células pela contagem por campos de células positivas na derme para cada monoclonal, contando se um mínimo de 10 campos para cada corte com objetiva de 40 e ocular de 10 , selecionando-se os campos onde havia maior concentração de células positivas. Esta seleçâo de campos evitou que áreas de derme sem infil trado fossem interpretadas como áreas de infil trado negativas para o tipo celular examinado. Um dos cortes do fragmento da biopsia congelada foi corado pela hematoxilina - eosina ( $\mathrm{HE}$ ) e as células inflamatórias do SFM foram quanti ficadas da mesma forma que a contagem reali zada para os monoclonais.

O outro fragmento era submetido ao método histoquímico para fosfatase ácida como previa mente descrito ${ }^{11}$. O fragmento era inicialmente fixado $24 \mathrm{~h}$ a $4^{\circ} \mathrm{C}$ em formol sacarose tamponado pH $6,8^{1}$. Em seguida transferido para soluçāo de Holt (sacarose $30 \mathrm{~g}$, goma arábica $1 \mathrm{~g}$ e água destilada $100 \mathrm{ml}$. Após 24 horas a $4^{\circ} \mathrm{C}$ o material foi lavado por $10 \mathrm{~min}$. em água corrente e depois de secar em papel de filtro, foi embebido em Tissue-Tek e congelado em nitrogênio líquido. Cor tes de $2 \mu$ de espessura foram obtidos (Cryo-Cut II), utilizando-se lâminas previamente albumi nizadas $(5 \%)$. As secçōes foram incubadas em uma soluçāo contendo tampão acetato $\mathrm{pH} 5.0$, $50 \mathrm{ml}$, naftol AS-BI fosfato (Sigma) $100 \mathrm{mg}$ dissolvidos em $0,5 \mathrm{ml}$ de dimetilformamida e $2 \mathrm{ml}$ de pararosanilina hexazotizada, por $30.60 \mathrm{~min}$. a $37^{\circ} \mathrm{C}$. Em seguida lavados 3 vezes em água destilada, 1 vez em PBS pH 7,4. Finalmente os cortes eram contrastados com verde metila $(1 \%)$ por 30-60 segundos para a coloração de fundo, lavados em água destilada e após secar montados com Permount. Para leitura das células com atividade para fosfatase ácida procedeu-se do mesmo modo que para os monoclonais.

As lâminas destinadas ao diagnóstico histológico (HE) assim como o Ziehl-Nielsen eram obtidas do fragmento destinado a histoquimica.

\section{Reagentes:}

- OKIa da linha Orthoclone (Ortho Pharmaceutical Co.). Identifica células $\mathrm{T}$ ativadas, macrófagos e linfócitos $\mathrm{B}$;

- OKM1 da linha Orthoclone (Ortho Pharma ceutical Co.). Identifica, monócitos, neutrófilos e macrófagos;

- Anti-MO (cedido por Dr. Van Voorhis - Uni versidade Rockefeller). Identifica monócitos. 
SARNO, E. N.; ALVARENGA, F. B. F.; VIEIRA, L. M. M. \& SOUZA, P. R. C de - Caracterizacao dus macrofagris presentes nas lesōes cutâneas da hanseníase: estudo por monoclonais.

- Anti-IgG de camundongo biotinilada obtida em cavalo (Vector Lab.);

- Avidina-Fluoresceina (Vector Lab.);

- Naftol AS-BI fosfato (Sigma);

- Dimetilformamida (Sigma);

- Pararosanilina hexazotizada (Sigma)*;

- Verde Metila (Merck);

* Soluçāo estoque de pararosanilina: pararosa nilina hidroclórica $2 \mathrm{~g}$, água deionizada 40 $\mathrm{ml}, \mathrm{HC} 12 \mathrm{~N}-10 \mathrm{ml}$. Pararosanilina hexazotizada $(\mathrm{PRH})$ : Soluçāo estoque de pararosanilina $2 \mathrm{ml}$ e nitrito de sódio $4 \%-2 \mathrm{ml}$.

\section{RESULTADOS}

A identificaçāo de células do SFM pela he matoxilina-eosina foi expressa como número total de células.

A avaliaçāo da atividade de fosfatase ácida que é uma enzima encontrada nos vacuólos lisossomais identifica células do SFM com uma coloraçāo vermelha citoplasmática dada sobre o substrato naftol AS-BI fosfato. Nos casos de tuberculóides (Fig. 1), raras células gigantes mostram citoplasma positivo, os macrófagos mostram positividade citoplasmática difusa mal de limitada. Algumas células com morfologia semelhante as epitelióides eram positivas, porém nāo se pode assegurar que todos o sejam. Nos casos virchowianos (Fig. 2) o citoplasma dos macró. fagos exibiam grandes vacúolos confluentes com conteúdo enzimático em geral concentrado na periferia vacuolar. Algumas células continham globias intra-vacuolares nos casos "bordeline" virchowianos predominavam macrófagos microvacuolares com atividade enzimática pronunciada.

A identificação de células positivas por imunofluorescência com os anticorpos monoclonais OKM1, anti-MO e anti-Ia era determinada por fluorescência em membrana ocupando toda a superfície celular como também segmentos da membrana. As células positivas para OKM1 nas formas tuberculóides eram pequenas e redondas (Fig. 3) tendo sob a imunofluorescência morfologia semelhante a da marcação de linfócitos em geral por anticorpos monoclonais. Algumas células maiores eram também marcadas de forma

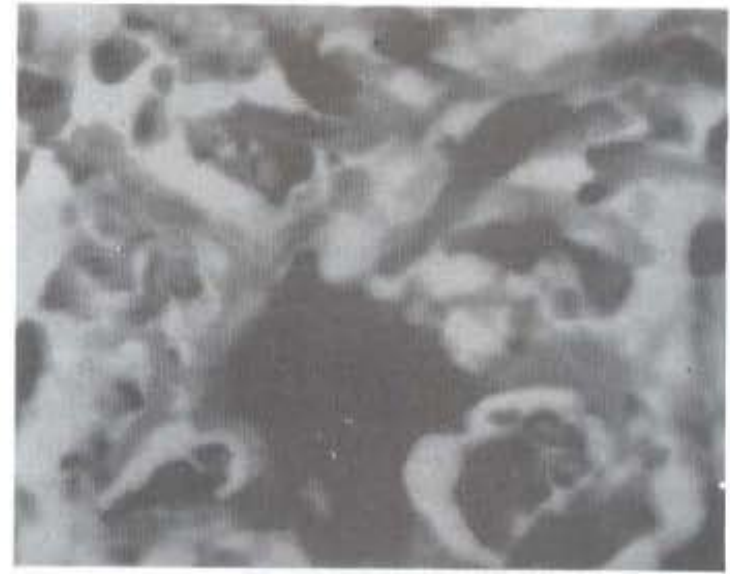

Fig. 1 - Granuloma tuberculoide contendo maerófagos, algu mas celulas epitelióldes e células gigantes apresentando ativi. dade fosfatase ácida. $40 \mathrm{X}$.

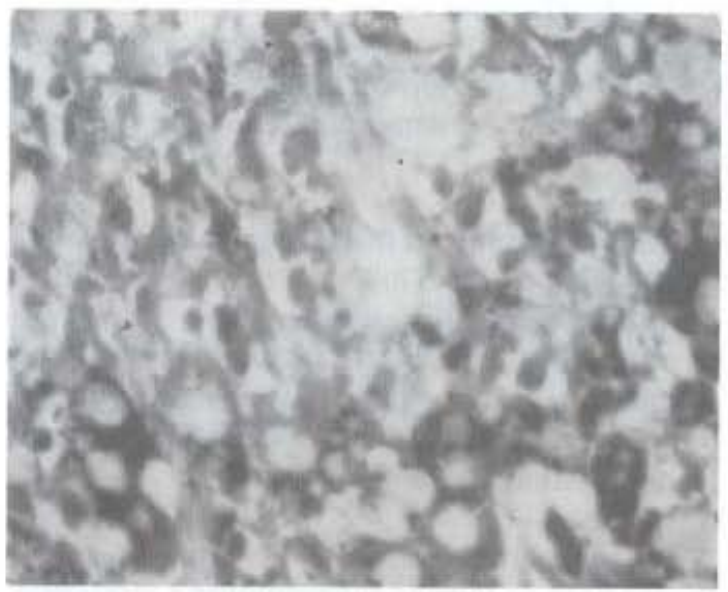

Fig. 2 - Foto 2: Lesâo lepromatosa mostrando macrófagos vacuolizados contendo atividade enzimatica fosfatase acida perivacuolar. $40 \mathrm{X}$.

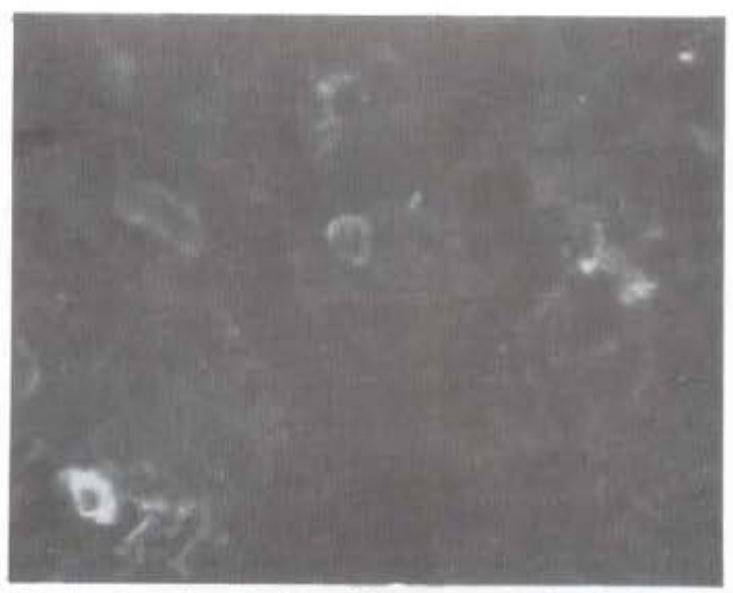

Fig. 3-Granuloma tuberculoide apresentando celulas isoladas positivas, Anticorpo monoclonal OKM1, 40X. 
SARNO, E N.; ALVARENGA, F'. B. F.: VIEIRA, L. M. M. \& SOUZA, P. R. C. de -.. Caracterizaçao dos macrótagos presentes

bastante tênue porém a correlaçāo morfológica com o HE nāo era precisa, nāo se podendo carac terizar as células epitelióides e gigante quanto à positividade para o OKM1.

Os macrófagos presentes nos casos virchowianos exibiam heterogeneidade com relação a ambos os antígenos monocitários detectados pe los monoclonais. A positividade variava de célu las com forte fluorescência à células negativas notando-se várias com positividade segmentar em membrana celular (Fig. 4), sem entretanto haver correlaçăo com a intensidade de fluorescência e a carga bacilar. Alguns destes macró fagos exibiam autofluorescência.

O número de cèlulas positivas para o OKM 1 e anti MO (Tabelas 1 e 2 ) era diverso, bem inferior ao total de células do SFM identificadas pelo HE e pelo FAC, cujo total de células positivas também era notavelmente inferior ao valor total do $\mathrm{HE}$.

A intensidade da fluorescencia de nembra na do OKIa era bem forte em relaçāo aos outros dois anticorpos utilizados (Fig. 6) e a quantidade de células bastante elevada (Tabelas 1 e 2). Estas células formavam amplos grupos corresponden do por vezes a totalidade de uma área do infil trado inflamatório (Fig. 6).

A comparação entre os percentuais encon trados para as formas tuberculóide e virchowia na (Tabela 3) nos mostra que o percentual de

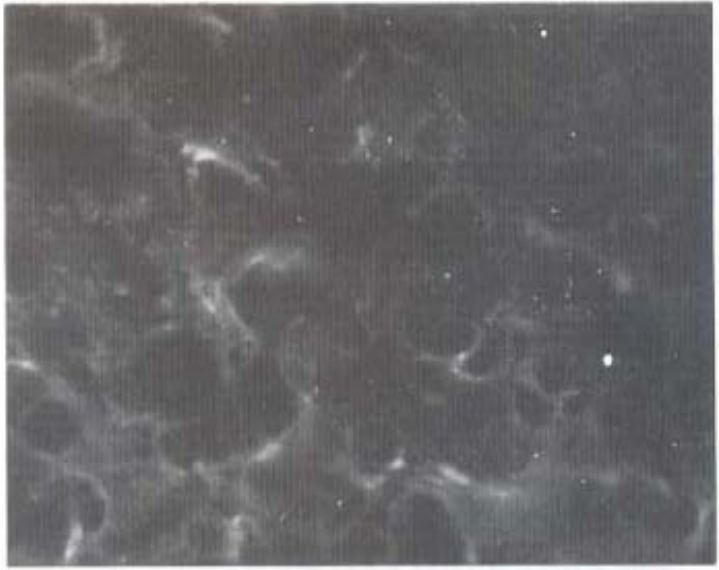

Fig. 4-Infiltrado de macrofago na lepra lepromatosa. Grande numero de celulas positivas com diferente intensidade. Anti corpo monoclonal OKM1, 40X

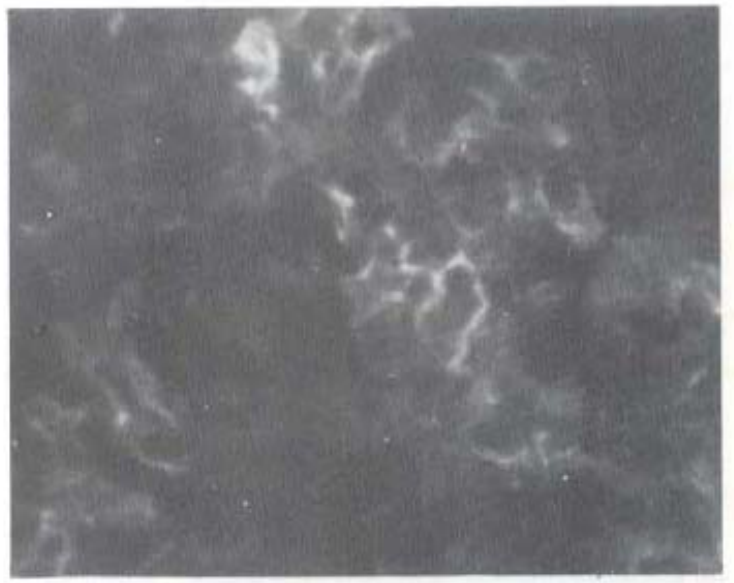

Fig. 5 - Mesmo caso anterior corado pelo anticorpo mono clonal Anti-MO, Quase todas as celulas såo positivas. $40 \mathrm{X}$.

TABLE 1

Distribuiçāo dos macrófagos identificados pelos monoclonais e por atividade de fosfatase acida nos casos de tuberculóides

\begin{tabular}{|c|c|c|c|c|c|}
\hline Nome & OKM 1 & Anti-MO & OKIa & FAC & $\mathrm{HE}$ \\
\hline MLS & $35 \pm 8$ & $34 \pm 7$ & $96 \pm 37$ & $106 \pm 71$ & $233 \pm 68$ \\
\hline JMG & $23 \pm 12$ & 0 & $42 \pm 16$ & $23 \pm 14$ & $321 \pm 58$ \\
\hline$J \mathrm{DH}$ & $24 \pm 4$ & $24 \pm 6$ & $69 \pm 18$ & $19 \pm 8$ & $235 \pm 43$ \\
\hline JMS & $29 \pm 11$ & $34 \pm 9$ & $53 \pm 27$ & $18 \pm 6$ & $348 \pm 66$ \\
\hline MF'S & $11 \pm 10$ & $3 \pm 7$ & $75 \pm 27$ & $45 \pm 15$ & $266 \pm 155$ \\
\hline NSG & $8 \pm 8$ & 0 & $61 \pm 20$ & $42 \pm 9$ & $277 \pm 114$ \\
\hline $\operatorname{ACS}$ & 0 & $6 \pm 1$ & $25 \pm 8$ & $35 \pm 6$ & $257 \pm 137$ \\
\hline MA & $36=5$ & $28 \pm 10$ & $37 \pm 5$ & $43 \pm 11$ & $180 \pm 46$ \\
\hline Média & $(20,75 \pm 12,28)$ & $(16,12 \pm 14,30)$ & $(57,25 \pm 21,41)$ & $\{41,37 \pm 26,49\}$ & $(264,62 \pm 49,22)$ \\
\hline
\end{tabular}

FAC - Atividade fosfatase acida.

0 - Nenhuma célula positiva. 
SARNO, E. N.; ALVARENGA, F. B. F.; VIEIRA, L. M. M. \& SOUZA, P. R. C de - Caracterização dos macrófagos presentes nas lesōes cutâneas da hanseníase: estudo por monoclonais. Rev. Inst. Med. trop. São Paulo, 30 (1): $45-50,1988$.

TABLE 2

Distribuiçāo dos macrofagos identificados pelos monoclonais OKMl e anti-MO e por atividade fosfatase ácida nos virchowianos

\begin{tabular}{|c|c|c|c|c|c|}
\hline Nome & OKM1 & Antimo & OKIa & $\mathrm{FAC}$ & $\mathrm{HE}$ \\
\hline FLM & $14 \pm 9$ & $6 \pm 6$ & $45 \pm 16$ & $43 \pm 16$ & $115 \pm 21$ \\
\hline GBC & $12 \pm 2$ & $12 \pm 6$ & $108 \pm 43$ & $120 \pm 59$ & $275 \pm 30$ \\
\hline IIR & $13 \pm 1$ & $34 \pm 6$ & $51 \pm 4$ & $36 \pm 9$ & $123 \pm 43$ \\
\hline JMC & $13 \pm 4$ & $10 \pm 4$ & $15 \pm 3$ & $36 \pm 11$ & $118 \pm 65$ \\
\hline ASP & $14 \pm 8$ & $45 \pm 10$ & $53 \pm 7$ & $158 \pm 18$ & $207 \pm 60$ \\
\hline APA & 0 & $1 \pm 1$ & 0 & $44 \pm 4$ & $211 \pm 58$ \\
\hline DMCO & $13 \pm 4$ & $23 \pm 4$ & $12 \pm 3$ & $81 \pm 23$ & $169 \pm 89$ \\
\hline JBN & $12 \pm 2$ & $19 \pm 2$ & $23 \pm 4$ & $90=22$ & $207 \pm 15$ \\
\hline Média & $11,37 \pm 4,35$ & $18,75 \pm 13,87$ & $38,37 \pm 32,04$ & $76 \pm 42,12$ & $178,12 \pm 53,44$ \\
\hline
\end{tabular}

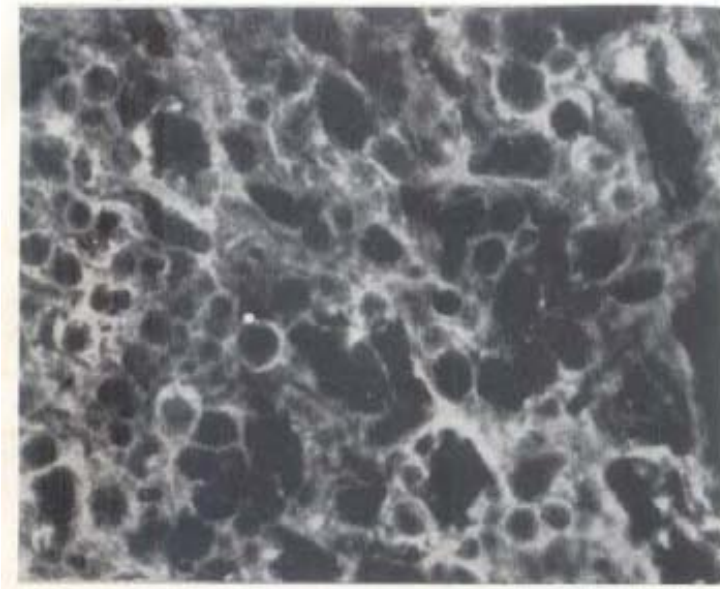

Fig. 6-Infiltrado de macrófagos em lesáo lepromatosa exibin do expressáo de antigeno la-like em quase todas as celulas. Anticorpo monoclonal anti-DR. $40 \mathrm{X}$.

células OKIa positivas era semelhante para ambos os grupos estudados embora este valor fosse pelo menos duas vezes maior que o encontrado com os marcadores monocitários, com os quais o percentual obtido foi baixo. Em relação a atividade de fosfatase ácida, nos casos de virchowianos $42,66 \%$ das células com identificação morfo lógica de fagocíticas mononucleares apresentavam atividade enzimática enquanto que apenas $15,63 \%$ das células nos casos tuberculóide eram positivas.

\section{DISCUSSĀo}

A utilização de anticorpos monoclonais na identificação de macrófagos presentes em lesōes
TABLE 3

Comparaçảo entre os percentuais obtidos nos casos de tuber culóides e virchowianos para cada marcador

\begin{tabular}{lcrcc}
\hline & OKM1 & Anti.MO & OKIa & FAC \\
\hline Casos T & 7,84 & 6,09 & 21,63 & 15,63 \\
Casos L & 6,38 & 10,52 & 21,54 & 42,73 \\
\hline
\end{tabular}

$\%=\frac{\text { Média de células positivas }}{\text { Média de células contadas no HE }} \times 100$

cutâneas da hanseniase demonstrou que essas células cons tituem uma populaçāo heterogênea.

Foi demonstrado anteriormente que 75 a $84 \%$ das células aderentes provenientes da população mononuclear sangüínea de pacientes com hanseníase eram identificadas por anticorpo anti-monócito (OKM1), não sendo feita a marcação das células nas lesōes ${ }^{6}$. Outros autores porém referem que o antígeno identificado pelo anti corpo OKM1 está presente em células histiocíticas, em lesões, sem variaçōes no espectro da doença ${ }^{5}$. No presente trabalho o número de células identificadas por anticorpos contra monócitos foi em geral muito menor quando comparado com a identificação pela coloração de rotina (HE). Isto pode ser devido ao fato da identificaçao de células do SFM pelo HE não ser precisa pois a morfologia em reaçōes inflamatórias e também neoplasias nos mostram que nem sempre a identificação morfológica é precisa por isso a necessidade de técnicas enzimáticas e imunohistológicas para caracterização de populaçóes celulares. 
SARNO, E. N.; ALVARENGA, F. B. F.; VIEIRA, L. M. M. \& SOUZA, P. R. C. de - Caracterizaç đ̆o dos macrófagos presentes nas lesōes cutâneas da hanseniase: estudo por monoclonais.

Rev. Inst. Med. trop. São Paulo, 30 (1): 45-50, 1988.

Outra explicação para o pequeno número de células do SFM marcadas pelos monoclonais é uma possível perda dos antígenos durante o pro cesso de maturação a partir dos monócitos. Na maioria dos casos o número de células com atividade enzimática também foi menor do que o total de células vistas no HE.

As observaçōes sugerem que cada um dos anti-monócitos aqui usados identifica antígenos diferentes embora não fosse possivel assegurar com nenhum deles a positividade para células epitelióides ou células gigantes com técnica de imunofluorescência, o que talvez pudesse ser visualizado com técnicas imunoenzimáticas como a imunoperoxidase, com coloraçào e contraste. Já a identificação pela atividade de fosfatase áci da a identificação morfológica pode ser feita, no tando-se inclusive positividade em células com morfologia epitelióide e em raras células gigan tes.

A diversidade de como as células de Virchow exibem positividade para os anticorpos marca dores de monócitos sugere que elas constituem uma populaçāo heterogênea, heterogeneidade que está não relacionada à carga bacilar já que tanto na forma LL quanto na BL o padrāo de positividade para as células de Virchow era se melhante.

Outro resultado in teressante é o número ele vado de células OKIa positivas encontrado em todos os casos com percentual semelhante nos grupos estudados, o que sugere que uma defi ciência de células apresentadoras de antígeno não deve ser um fator importante na determinação da baixa resposta imune ao M. leprae. como foi entre outras hipóteses, questionado por outros autores ${ }^{2}$

\section{SUMMARY}

\section{Characterization of mononuclear phagocytes in} leprosy skin lesions: a monoclonal study.

The skin lesions from 16 leprosy patients we re studied by immunofluorescence technique using monoclonal antibodies against monocytes (OKM1 and Anti-Mo) and Ia-like antigen. Acid phosphatase activity was evaluated using naph thol AS-BI phosphate as substrate.

The macrophages seem to be a heteroge neous population in concern with the antigens here studied as well as the enzimatic activity.
Ia-like antigen was expressed in a great number of cells throughout the clinical spectrum.

\section{REFERENCIAS BIBLIOGRAFICAS}

1. BOLTON, W. K. \& MESNARD, R. M. - New technique of kidney tissue processing for immunofluorescence microscopy: formol sucrose/gum sucrose/paraffin. Lab. Invest. 47 : $206-213,1982$

2. GODAL, T. - Immunological aspects of leprosy: present status. Progr. Allergy, 25: $211.242,1978$

3. MODLIN, R, L.; HOFMAN, F. M.; HORWITZ, D. A.: HUS MANN, L. A.; GILLIS, S.; TAYLOR, R. \& THOMAS, R. - In situ identification of cells in human leprosy granulomas with monoclonal antibodies to interleukin 2 and its receptor. J. Immunol. 132: 3085-3090, 1984.

4. NARAYANAN, R. B: BHUTANI, L. K : SHARMA, A. K \& NATH, I. - T cell subsets in leprosy lesions: in situ cnaracterization using monoclonal antibodies. Clin. exp. Immunol., 51: 421-429, 1983.

5. NOGUEIRA, N; KAPLAN, G.; LEVY, E.; SARNO, E. N.; RISHNEU, R.: GRANELLI.PIPERNO. A.; VIEIRA, L.; GOULD, V. C.: LEVIS, W.; STEINMAN, R.; YIP, Y. K. \& COHN, Z.A. - Defective interferon production in leprosy. Reversal with antigen and interleukin-2. J. exp. Med., 158: $2165-2170,1983$

6. REINHERZ, E. L; KUNG, P. C; PESANDO, J M ; RITZ, J.; GOLDSTEIN, G. \& SCHLOSSMANN, S. F. - Ia determinants on human T.cell subsets defined by monoclonal antibody: activation stimuli required for expression. $\mathbf{J}$. exp. Med., 150: $1472-1482,1979$

7. REINHERZ, E. L. \& SCHLOSSMAN, S. F. - The differen tiation and function of human T lymphocytes. Cell, 19: $821.825,1980$

8. RIDLEY, D. S. \& JOPLING, W. H. - Classification of leprosy according to immunity: a five group system. Int. J. Leprosy, 34: 255-273, 1966.

9. SARNo, E. N. \& VIEIRA, L. M. M. - Métodos histoquí micos para identificação de linfócitos e macrófagos. Mem. Inst. Osw. Cruz, 79: 59 -62, 1984

10. SPRINGER, T. A. - Monoclonal antibodies as tools for the study of mononuclear phagocytes. In: ADAMS, D. O.; EDELSON, P. J. \& KOREN, J., ed. Methods for studying mononuclear phagocytes. New York. Academic Press, 1981. p. 305-313.

11. VAN FURT, R. -- Identification of mononuclear phagocytes: overview and definitions. In: ADAMS, D. O.; EDELSON, P. J. \& KOREN, J., ed. Methods for studying mononuclear phagocytes. New York, Academic Press, 1981. p. $243-251$.

12. VAN VOORHIS, W. C.: KAPLAN, G.: SARNO. E. N.: HOR WITZ, M. A ; STEINMAN, R. M.; LEVIS, W. R ; NOGUEI RA N ; HAIR, L.; GATTASS, C.; R ; ARRICH, B. A. \& COHN, Z. A. - The cutaneous infiltrates of leprosy. New Engl. J. Med., 307: 1593-1597, 1982

Recebido para publicaçāo em 16/02/1987 